\title{
Thickness of the Schneiderian membrane and its correlation with anatomical structures and demographic parameters using CBCT tomography: a retrospective study
}

Demos Kalyvas ${ }^{*}$, Andreas Kapsalas $^{1}$, Sofia Paikou ${ }^{1}$ and Konstantinos Tsiklakis ${ }^{2}$

\begin{abstract}
Background: The aims of the present study were to determine the thickness of the Schneiderian membrane and identify the width of the maxillary sinus, which is indicated by the buccal and lingual walls of the sinus angle between. Furthermore, to investigate the possibility of a correlation between the aforementioned structures and also other anatomical and demographic parameters using CBCTs for dental implant surgical planning.

Methods: The study included CBCT images of 76 consecutive patients with field-of-view $15 \times 12$ or $12 \times 8 \mathrm{~cm}$. Reformatted cross-sectional CBCT slices were analyzed with regard to the thickness of the Schneiderian membrane designated by the medial and the lateral walls of the sinus, in three different standardized points of reference. Age, gender, and position of the measurement were evaluated as factors that could influence the dimensions of the anatomical structures, using univariate and multivariate random effects regression model.
\end{abstract}

Results: The mean thickness of the Schneiderian membrane was $1.60 \pm 1.20 \mathrm{~mm}$. The average thickness revealed now differentiation by age $(p=0.878)$, whereas gender seemed to influence the mean thickness $(p=0.010)$. Also, the thickness of the Schneiderian membrane increased from medial to distal $(p=0.060)$. The mean value of the angle designated by buccal and lingual walls of the sinus was $73.41 \pm 6.89^{\circ}$. The angle measurements revealed no correlation with age, but a tendency towards lower mean angles in females ( $2.5^{\circ}$ on average, $\left.p=0.097\right)$. According to the anatomical position of the measurement, a differentiation was also detected. No correlation between thickness of the Schneiderian membrane and the angle of the walls of the sinus was concluded ( $p=0.662)$.

Conclusions: This study demonstrated that the thickness of the Schneiderian membrane and the width of the maxillary sinus can only be affected by gender and anatomical position, but not by the age of the patient.

Keywords: Schneiderian membrane, Sinus, Thickness, Width, CBCT

\footnotetext{
* Correspondence: demkal@dent.uoa.gr

'Department of Oral and Maxillofacial Surgery, School of Dentistry, National and Kapodistrian University of Athens, Greece, Thivon 2 str, 11527 Athens, Greece

Full list of author information is available at the end of the article
} 


\section{Background}

The maxillary sinus is the largest of the paranasal airfilled spaces, and it develops firstly in utero [1, 2]. Anatomically, the maxillary sinus is a pyramid-shaped cavity located in the facial skull with a mean volume of $12.5 \mathrm{~mL}$ (min $5 \mathrm{~mL}$ and $\max 22 \mathrm{~mL}$ ) [2-6]. The size, the shape, and the wall thickness of every maxillary sinus not only vary among the population, but also between the two sides of an individual skull [6].

The Schneiderian membrane is the mucous membrane that covers the inner part of the maxillary sinus cavity [7]. Histologically, it consists of an overlaid periosteum with a thin layer of a pseudo-stratified ciliated epithelium and highly vascularized connective tissue [1, 7]. According to Kim et al. 2009, it has been proved that mesenchymal stem cells from the sinus membrane have an ability of bone formation, which plays a vital role in sinus floor elevation procedures [8]. Many studies have measured the thickness of the Schneiderian membrane using different methods such as cadaver examinations, CTs, and CBCTs. Normally, the thickness of the Schneiderian membrane is approximately $1 \mathrm{~mm}$ $[6,9]$. However, in everyday clinical practice, mucosal thickening of the maxillary sinus is a common radiographic finding in asymptomatic patients; therefore, mucosal lining of more than $4 \mathrm{~mm}$ is considered to be pathological $[6,9]$.

When planning any surgical treatment for the maxilla that includes the posterior region, not only the dimensions and abilities of the Schneiderian membrane, but also the anatomical variations of the maxillary sinus are very significant for every clinician. Cone-beam computed tomography provides essential three-dimensional information regarding the inner part of the maxillary sinus in order to increase the success rate of every surgical procedure and, simultaneously, in order to limit the intraand post-operative complications.

In the international literature, there is a limited number of studies that quantify the dimensions of the Schneiderian membrane using CBCTs. Therefore, the aim of the present retrospective study is to measure the thickness of the Schneiderian membrane and to identify the width of the maxillary sinus, which is indicated by the angle between the buccal and lingual walls of the sinus in a given height, using $\mathrm{CBCT}$ imaging. Furthermore, the present study detects possible

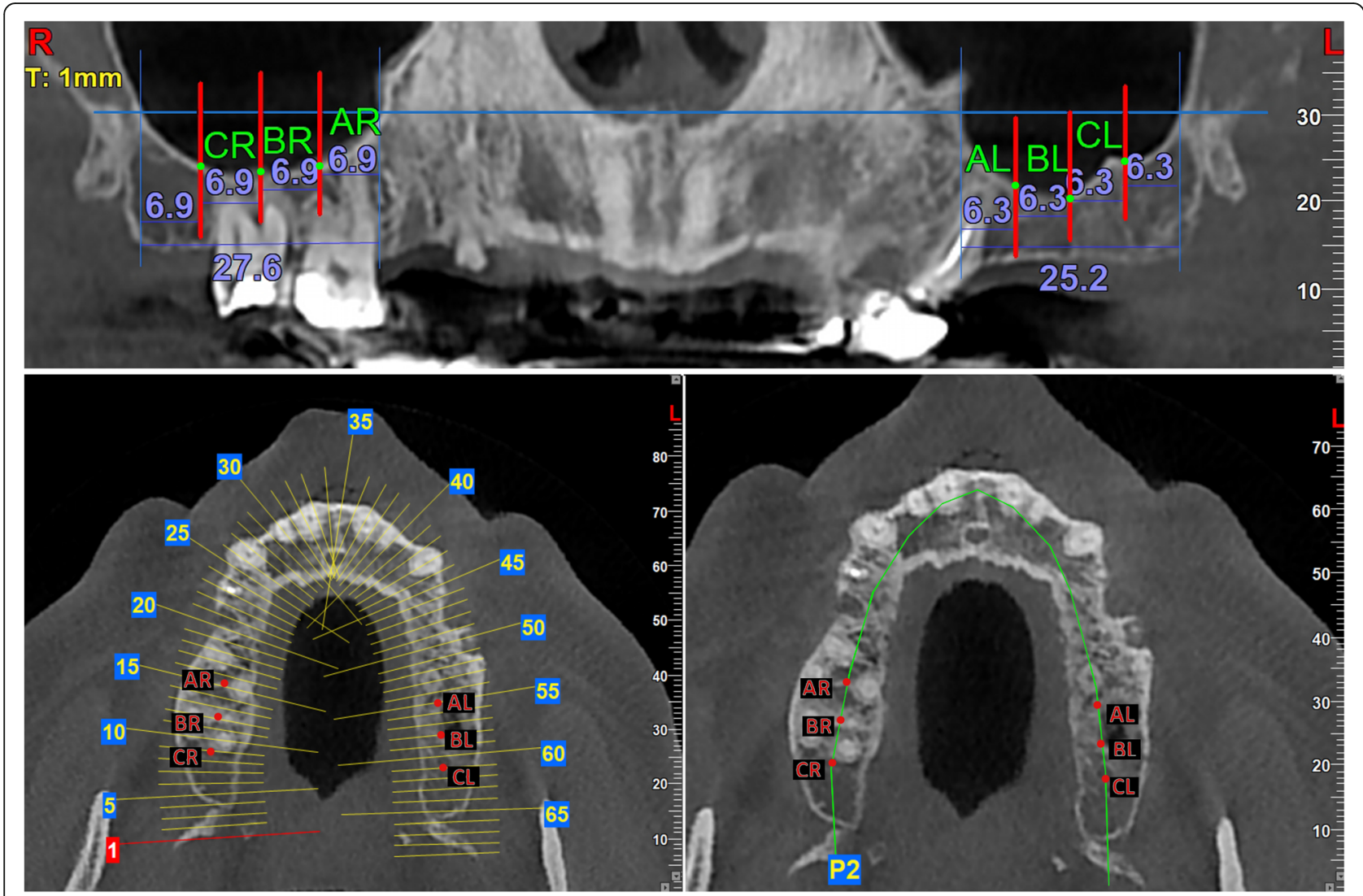

Fig. 1 Demonstration of the method used in the panoramic image to divide the sinus in four equal parts and find three fixed points for the measurements. Also, these fixed points in the horizontal plane with and without sections 

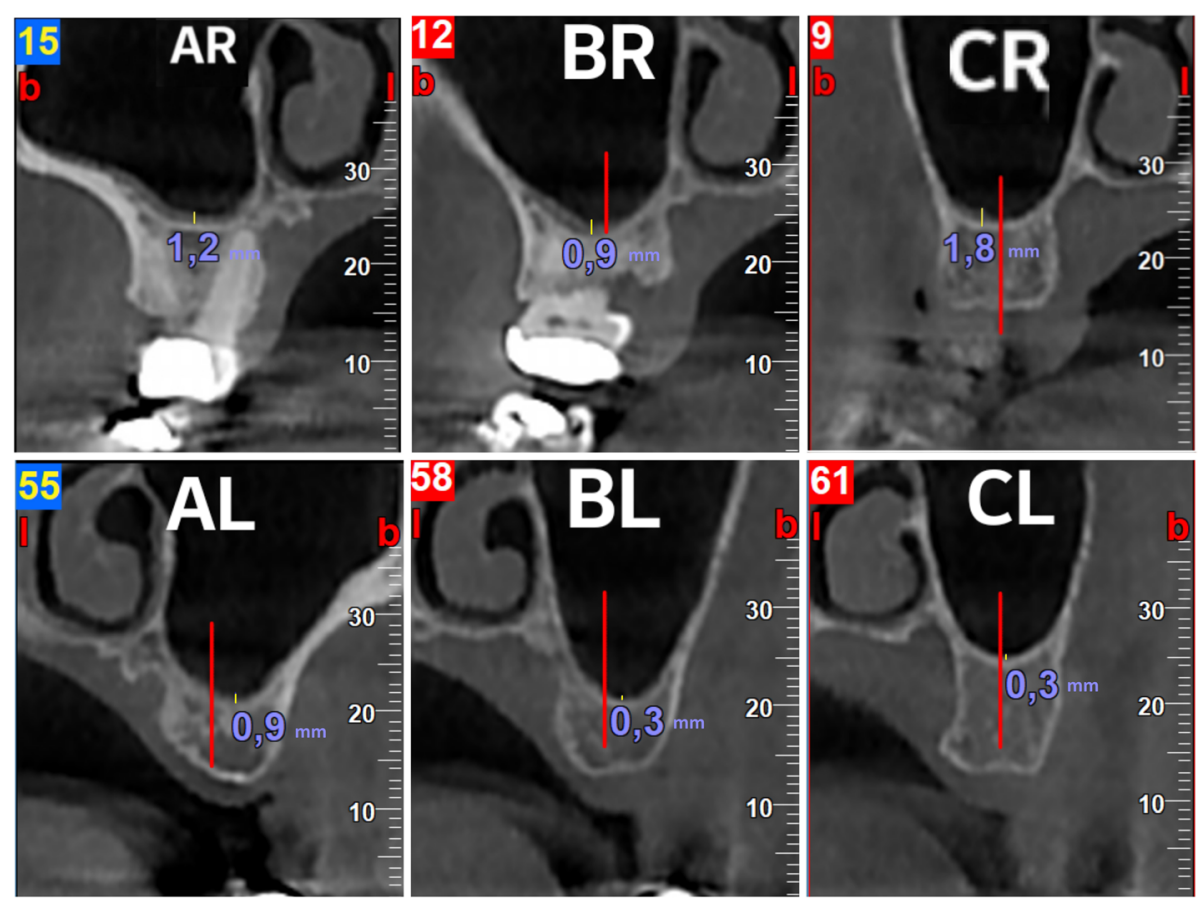

Fig. 2 Demonstration of the method used to measure the thickness of the Schneiderian membrane in the cross-sectional images for each of the three fixed points

correlations between the aforementioned factors and also between each of these factors with anatomical locations and demographic parameters.

\section{Methods}

\section{Patient selection}

The study sample included 76 patients, of which 39 were females and 37 were males. In total, 120 sinuses (44 both left- and right-sided, 21 right-sided, and 11 left-sided) were evaluated as suitable for the present study and were measured. The total sample was classified in four age groups (below 45 years, 45-54 years, 54-64 years, and over 65 years of age). The mean age value of the sample is 58 years (ranging from 19 to 65 years of age).

All patients were Greek adults, and all CBCT examinations were performed to evaluate the posterior maxilla for future implant surgery. All patients were either patients of our clinic or had been referred to our clinic by their private dentist for implant or other pre-implant surgery. The minimum acceptable alveolar process was $5 \mathrm{~mm}$. Patients with previous implant therapy or/and maxillary sinus augmentation in their history as well as patients with active periodontal disease, cysts, polyps, sinusitis, allergic rhinitis, or other pathological entities in their maxillary sinuses were excluded from our study. Other exclusion criteria were the presence of systematic diseases impacting the metabolism and quality of the bones in patients' history, such as thyroid disease, hyperparathyroidism, diabetes, chronic renal disease, osteoporosis, and no development or acquired craniofacial or neuromuscular deformities. None of the patients previously or currently received medication including vitamin $\mathrm{D}$, human growing hormone $(\mathrm{HGH})$, or bisphosphonates. All the collected data were anonymous.

\section{Imaging procedure}

The CBCT images were obtained with NewTom VGI Tomograph (NewTom, Verona, Italy) with a voxel size of $0.3 \mathrm{~mm}$. Operating parameters were set at $5.28 \mathrm{~mA}$, $110 \mathrm{kV}$, exposure time $3.60 \mathrm{~s}$, and field of view (FOV) of $15 \times 12$ or $12 \times 8 \mathrm{~cm}$. Panoramic reformatted images with thickness of $1 \mathrm{~mm}$ were chosen for the present study.

All measurements were performed in millimeters using the ruler contained in the NNT Viewer'.

The distance between the medial and the lateral walls of the maxillary sinus in the panoramic reformatted images was divided in four equal segments. Thus, three points were created; $A R, B R$, and $C R$ for the right sinus and $\mathrm{AL}, \mathrm{BL}$, and $\mathrm{CL}$ for the left sinus (Fig. 1). For each of the aforementioned points, a cross section of $1 \mathrm{~mm}$ thickness was performed in 


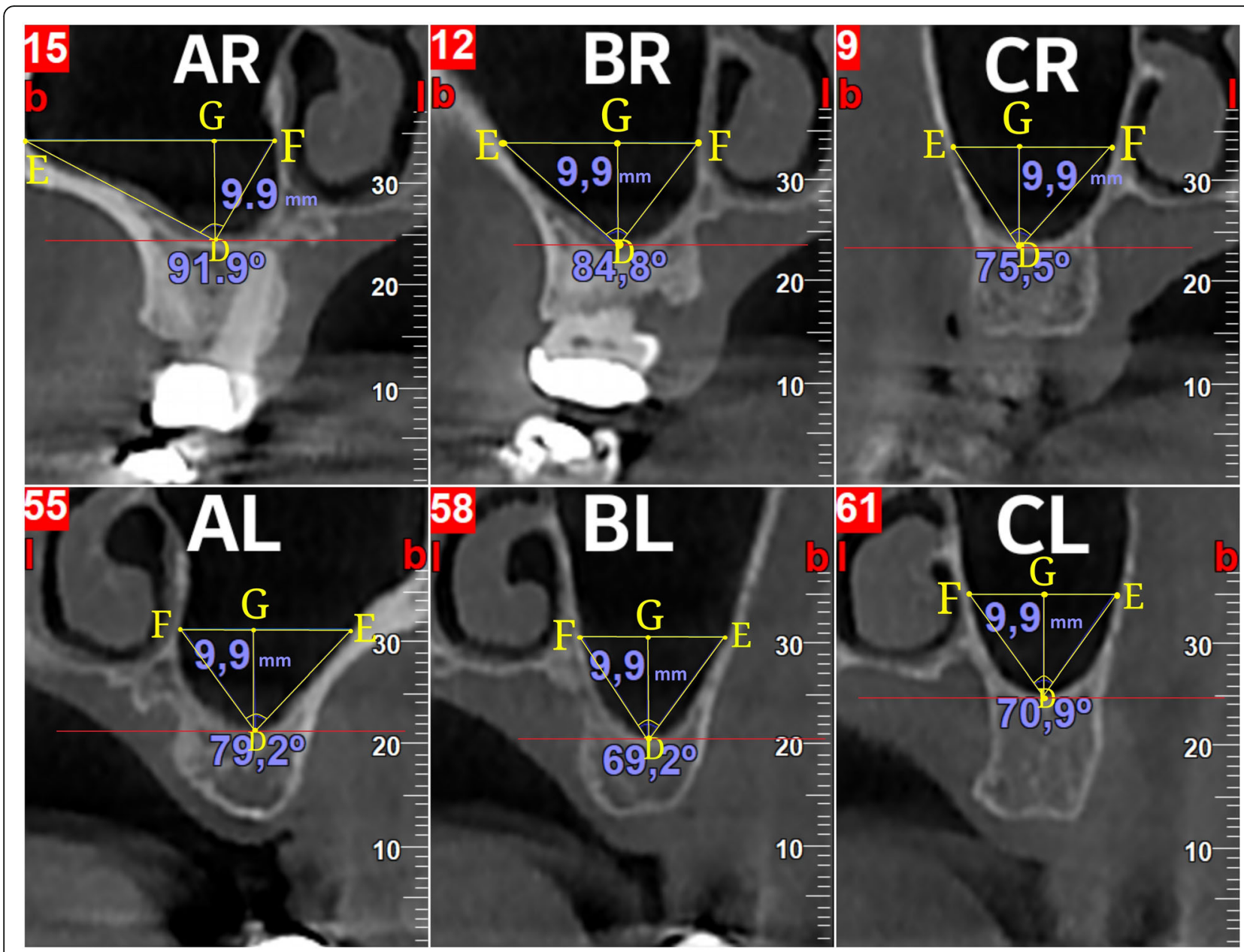

Fig. 3 Demonstration of the method used to measure the angle designated by the buccal and lingual walls of the sinus angle for each of the three fixed points in a given height

the middle of the alveolar bone. In the cross-sectional images, the thickness of the Schneiderian membrane was measured in the deepest point of the sinus floor (point D). Thus, three different measurements were performed for each sinus (Fig. 2).
These three cross-sectional images, in which the thickness of the Schneiderian membrane was previously measured, were also used for the measurement of the angle of the maxillary sinus. A segment DG (point $\mathrm{D}$ is the deepest point of the floor of the

Table 1 Sinuses' thickness by gender and overall

\begin{tabular}{|c|c|c|c|c|}
\hline & \multicolumn{3}{|l|}{ Sex } & \multirow[b]{3}{*}{$p$ value } \\
\hline & Male & Female & Overall & \\
\hline & Mean (SD) & Mean (SD) & Mean (SD) & \\
\hline Thickness (mm)-AR & $2.06(1.54)$ & $1.36(2.09)$ & $1.73(1.84)$ & 0.131 \\
\hline Thickness (mm)-BR & $1.77(1.43)$ & $1.00(0.82)$ & $1.40(1.23)$ & 0.010 \\
\hline Thickness (mm)-CR & $1.54(1.06)$ & $0.77(0.61)$ & $1.17(0.95)$ & 0.001 \\
\hline Thickness (mm)-AL & $2.13(1.96)$ & $1.64(2.54)$ & $1.88(2.28)$ & 0.431 \\
\hline Thickness (mm)-BL & $2.02(2.09)$ & $1.46(1.08)$ & $1.72(1.64)$ & 0.210 \\
\hline Thickness (mm)-CL & $1.72(1.58)$ & $1.26(1.18)$ & $1.48(1.39)$ & 0.226 \\
\hline Average thickness $(\mathrm{mm})$ _all points & $1.95(1.28)$ & $1.24(1.02)$ & $1.60(1.20)$ & 0.010 \\
\hline
\end{tabular}


Table 2 Average thickness by age group

\begin{tabular}{|c|c|c|c|c|c|c|}
\hline & \multicolumn{4}{|l|}{ Age (years) } & \multirow[b]{2}{*}{ Overall } & \multirow[b]{3}{*}{$p$ value } \\
\hline & $<45$ & $45-54$ & $55-64$ & $65+$ & & \\
\hline & $N(\%)$ & $N(\%)$ & $N(\%)$ & $N(\%)$ & $N(\%)$ & \\
\hline \multirow[t]{2}{*}{ Total } & $14(100.0)$ & $14(100.0)$ & $28(100.0)$ & $20(100.0)$ & $76(100.0)$ & \\
\hline & Mean (SD) & Mean (SD) & Mean (SD) & Mean (SD) & Mean (SD) & $p$ value \\
\hline Average thickness (mm)—overall & $1.55(1.21)$ & $1.86(1.57)$ & $1.61(1.25)$ & $1.45(0.86)$ & $1.60(1.20)$ & 0.878 \\
\hline
\end{tabular}

maxillary sinus) is created, vertical to the horizontal plane with stable length equal to $9.9 \mathrm{~mm}$. The mean of $9.9 \mathrm{~mm}$ was chosen, because of a limitation of the $\mathrm{NNT}^{\circ}$ software's limitation. A linear segment EGF (point $\mathrm{E}$ is the point where the segment EGF intersects with the buccal wall of the maxillary sinus, and point $F$ is the point where the segment EGF intersects with the lingual wall of the maxillary sinus) is created which vertical to segment DG and parallel to the horizontal plane. The points $\mathrm{D}, \mathrm{E}$, and $\mathrm{F}$ designate a triangle named DEF. The angle which is measured is EDF (Fig. 3).

Using the built-in ruler of the NNT Viewer ${ }^{\circ}$, we measured the angle EDF for each cross-sectional image created by the aforementioned method. This angle indicates the width of the maxillary sinus in each location. As this angle increases, so does the width of the maxillary sinus.

According to the value of this angle, the sinus width was classified in one of the three following groups (small-, moderate-, and large-sized sinus):

- Angle $\leq 65^{\circ}$ : small

- $65^{\circ}<$ angle $<80^{\circ}$ : moderate

- Angle $\geq 80^{\circ}$ : large

\section{Evaluation of the images}

The CBCT images were initially evaluated by an oral surgeon and then they were re-evaluated and measured by two experienced dentists who were involved in the patients' treatment and follow-up. In case of any disagreement, both parties re-evaluated and remeasured the related $\mathrm{CBCT}$ imaging.

\section{Statistical analysis}

All analyses were performed using Stata version 13.1 (Stata Corp., TX, USA).

\section{Results}

The mean value of the overall average thickness is 1.60 $\pm 1.20 \mathrm{~mm}$ (males $1.95 \pm 1.28 \mathrm{~mm}$ and females $1.24 \pm$ $1.02 \mathrm{~mm}$ ) (Table 1).

The average thickness of the membrane also showed no tendency for differentiation by age group $(p=0.878)$ (Table 2).

The statistical analysis also shows a clear tendency towards lower values when checking from point AR to point $C R$ and from point $A L$ to point $C L$, which means that the average thickness of the membrane increases from medial to distal. $(p=0.060)$ (Table 3).

The average mean value of the angle of the maxillary sinus in cross sections was $73.41 \pm 6.89^{\circ}$, revealing high prevalence of moderate-shaped sinuses (average mean angle value $74.65 \pm 8.08$ for the male group and $72.11 \pm$ 5.17 for the female group) (Table 4).

The angle of the sinus also shows no association with age (Table 5).

On the contrary, it was proven that there is a tendency towards lower angle values in the female group $\left(2.5^{\circ}\right.$ on average, $\left.p=0.097\right)$. It was also shown that at the points $\mathrm{BR}$ and $\mathrm{BL}$, the angles were statistically significantly higher than those at the points $A R$ and $\mathrm{AL}$, of the order of $10^{\circ}(p<0.001)$, but at the points $\mathrm{CR}$ and $\mathrm{CL}$ the difference is of $2.2^{\circ}(p=0.051)$. No association between thickness of the membrane and the angle (width) of the current position in the sinus was detected $(p=0.662)$ (Table 6).

Table 3 Thickness by point of measurement (all measurements)

\begin{tabular}{|c|c|c|c|c|c|}
\hline & \multicolumn{5}{|l|}{ Position } \\
\hline & $1(\mathrm{AR} / \mathrm{AL})$ & 2(BR/BL) & $3(\mathrm{CR} / \mathrm{CL})$ & Overall & \\
\hline & $N(\%)$ & $N(\%)$ & $N(\%)$ & $N(\%)$ & $p$ value \\
\hline \multirow[t]{2}{*}{ Total } & $120(100.0)$ & $120(100.0)$ & $120(100.0)$ & $360(100.0)$ & \\
\hline & Mean (SD) & Mean (SD) & Mean (SD) & Mean (SD) & $p$ value \\
\hline Thickness (mm) & $1.8(2.0)$ & $1.6(1.4)$ & $1.3(1.2)$ & $1.6(1.6)$ & 0.060 \\
\hline
\end{tabular}


Table 4 Sinuses' angles by gender and overall

\begin{tabular}{|c|c|c|c|c|}
\hline & \multicolumn{3}{|l|}{ Gender } & \multirow[b]{3}{*}{$p$ value } \\
\hline & Male & Female & Overall & \\
\hline & $N(\%)$ & $N(\%)$ & $N(\%)$ & \\
\hline \multirow[t]{2}{*}{ Sinuses measured } & $21(53.8)$ & $23(62.2)$ & $44(57.9)$ & \\
\hline & Mean (SD) & Mean (SD) & Mean (SD) & $p$ value \\
\hline Angle $\left({ }^{\circ}\right)-A R$ & $71.79(16.56)$ & $64.13(12.09)$ & $68.14(14.99)$ & 0.039 \\
\hline Angle $\left({ }^{\circ}\right)-B R$ & $80.34(9.56)$ & $78.60(5.63)$ & $79.51(7.92)$ & 0.380 \\
\hline Angle $\left({ }^{\circ}\right)-C R$ & $71.06(6.82)$ & $71.64(6.02)$ & $71.34(6.41)$ & 0.719 \\
\hline Angle $\left({ }^{\circ}\right)$-AL & $73.87(14.70)$ & $69.08(12.43)$ & $71.34(13.64)$ & 0.197 \\
\hline Angle $\left({ }^{\circ}\right)-B L$ & $80.34(8.21)$ & $79.25(7.83)$ & $79.77(7.96)$ & 0.616 \\
\hline Angle $\left({ }^{\circ}\right)-C L$ & $72.33(8.15)$ & $72.59(6.04)$ & $72.47(7.05)$ & 0.890 \\
\hline Average angle $\left({ }^{\circ}\right)$-all points & 74.65 (8.08) & $72.11(5.17)$ & $73.41(6.89)$ & 0.109 \\
\hline
\end{tabular}

\section{Discussion}

It is very important to pre-operatively evaluate the thickness of the Schneiderian membrane to plan the surgical procedure in the region that involves the membrane, such as a sinus lift augmentation, which increases the possibility of membrane perforation or other complications.

The present study assumed that the average thickness of the Schneiderian membrane is $1.60 \pm 1.20 \mathrm{~mm}$.

There are many studies which estimate the average thickness of the mucosa of the maxillary sinus, some of which have used CBCTs while others have not. These studies are presented in Table 7 . These values are not completely different to the results of the present study. From these studies, we can conclude that, clearly, there is variability regarding the thickness of the Schneiderian membrane. This means that a clinician cannot collect information about the thickness of a sinus membrane by patient sex, side, or age.

In this study, it was detected that $27.5 \%$ of the measurements made (99 out of 360) were more than $2 \mathrm{~mm}$. However, all X-ray examinations that showed a visually detectable pathology were excluded from our study. For this reason, our study cannot conclude that the limit of $2 \mathrm{~mm}$ is an accurate limit to evaluate a sinus membrane as healthy or pathological. The limit of $2 \mathrm{~mm}$ as a criterion is used by Shanbhag et al. 2014, Ji-Young Yoo et al. 2011, Janner et al. 2011, and Cagici et al. 2008 [10-13]. On the contrary, Eggesbo et al. 2006 and Cakur et al. 2011 set the limit of $4 \mathrm{~mm}$ as a safe threshold to evaluate a sinus membrane as pathological $[9,14]$. Furthermore, Lozano-Carrascal et al. 2017 accept a threshold of $3 \mathrm{~mm}$ of membrane thickness for pathology existence [15]. In our study, the membrane thickness of $6.94 \%$ of our sample was over $4 \mathrm{~mm}$. For this reason, we can accept a thickness over $4 \mathrm{~mm}$ as a safer limit to evaluate if there is a pathology in the sinus or not.

Comparing the thickness of the membrane between the two genders, males seem to have thicker membranes than females. Vallo et al. 2010, Janner et al. 2011, Ji-Young Yoo et al. 2011, Cakur et al. 2013, and Jildirim et al. 2017 [9, 11, 12, 16, 17] also come to this conclusion. Our study assumed that this difference is of the order of $40 \%$. On the contrary, Pazera et al. 2010 concluded that there is no significant difference between thickness of the mucosa and gender $(p=0.294)[18]$.

Table 5 Angle of the walls of the sinus by age groups

\begin{tabular}{|c|c|c|c|c|c|c|}
\hline & \multicolumn{4}{|l|}{ Age (years) } & \multirow[b]{2}{*}{ Overall } & \multirow[b]{3}{*}{$p$ value } \\
\hline & $<45$ & $45-54$ & $55-64$ & $65+$ & & \\
\hline & Mean (SD) & Mean (SD) & Mean (SD) & Mean (SD) & Mean (SD) & \\
\hline Angle $\left({ }^{\circ}\right)$-AR & 70.05 (17.57) & $68.92(15.67)$ & $67.43(12.05)$ & 67.29 (17.30) & 68.14 (14.99) & 0.958 \\
\hline Angle $\left({ }^{\circ}\right)-B R$ & $80.63(8.11)$ & 78.50 (10.66) & 78.58 (5.70) & 80.74 (8.43) & 79.51 (7.92) & 0.766 \\
\hline Angle $\left({ }^{\circ}\right)-C R$ & 70.80 (7.38) & 71.31 (7.73) & $69.57(5.31)$ & 73.93 (5.69) & 71.34 (6.41) & 0.190 \\
\hline Angle $\left({ }^{\circ}\right)$-AL & 76.95 (9.55) & 67.30 (12.39) & 73.75 (14.11) & 66.01 (14.75) & 71.34 (13.64) & 0.136 \\
\hline Angle $\left({ }^{\circ}\right)-B L$ & 79.35 (6.37) & 82.81 (10.87) & 79.61 (7.65) & 78.67 (8.11) & 79.77 (7.96) & 0.694 \\
\hline Angle $\left({ }^{\circ}\right)-C L$ & 73.71 (8.66) & 74.44 (4.38) & 71.27 (7.52) & 72.19 (6.50) & 72.47 (7.05) & 0.671 \\
\hline
\end{tabular}


Table 6 Results from a multivariable random effects regression model of all angles on age (in groups) gender and point of measurement

\begin{tabular}{llll}
\hline Factor & Difference & $95 \% \mathrm{Cl}$ & $p$ value \\
\hline $\begin{array}{c}\text { Age (years) } \\
<45^{\mathrm{a}}\end{array}$ & 0 & & \\
$45-54$ & -0.9 & $(-5.7,3.9)$ & 0.724 \\
$55-64$ & -1.4 & $(-5.5,2.8)$ & 0.520 \\
$65+$ & -0.6 & $(-5.0,3.9)$ & 0.806 \\
Gender & & & \\
Male & 0 & & \\
Female & -2.5 & $(-5.4,0.5)$ & 0.097 \\
Position & & & \\
1 (AR/AL) & 0 & & $<0.001$ \\
2(BR/BL) & 10.0 & $(7.8,12.3)$ & 0.051 \\
3 (CR/CL) & 2.2 & $(-0.0,4.5)$ & \\
\hline
\end{tabular}

${ }^{a}$ Reference category

The aforementioned differences can be attributed to the fact that every study has evaluated different populations and has also set different criteria in the selection of their sample.

In our study, there is no statistically significant influence when comparing the thickness of the mucosa and age $(p=0.878)$. Janner et al. 2010, Vallo et al. 2010, and Jildirim et al. 2017 also come in accordance with our results $[12,16,17]$. The age factor does not seem to affect the anatomical characteristics of the sinus. Unlike a state of inflammation, allergy, smoking of the patient does not affect the sinus thickness or wideness [6].

As regards the width of the maxillary sinus, the mean angle value was found to be $73.4 \pm 6.9^{\circ}$. It seems that there is a tendency towards greater angle values in the male group, but the difference is not statistically significant in order to conclude that wider angles and widths exist in male patients. The aforementioned results can be also associated with the results of the study of Gosau et al. 2009, which showed that female sinuses tend to have lower average volume values than male sinuses [4]. The study of Lozano-Carrascal et al. 2017 also measured the same angle but only in the region of the upper first molar and found a mean value of $73.39 \pm 15.23^{\circ}$ [15]. The present study is more accurate because the mean angle results from three different measurements taken from three different points of the maxillary sinus.

In the present study, it was also concluded that the width of the sinus increases from mesial to distal. Male sinuses had higher prevalence of high angle values compared to female sinuses, but the majority of angle values and widths was characterized as moderate.

In an attempt to correlate the membrane biotype regarding thickness with the sinus width, it was proven that there is no correlation between the thickness and width of the sinus $(p=0.695)$.

\section{Conclusions}

In conclusion, the present study demonstrated that male patients tend to have a thicker membrane than female patients. The angles of the sinus seemed to increase in

Table 7 All studies measuring the thickness of the Schneiderian membrane [5, 7, 9, 12, 15, 17-25]

\begin{tabular}{llll}
\hline Authors & Year of study & Method of study & Results \\
\hline Tos and Mogesen et al. & 1979 & Cadavers & $0.3-0.8 \mathrm{~mm}$ \\
Aimetti et al. & 2008 & Endoscopically & $0.97 \pm 0.36 \mathrm{~mm}$ \\
Pommer et al. & 2009 & Cadavers & $0.09 \pm 0.045 \mathrm{~mm}$ \\
Janner et al. & 2010 & CBCTs & $2.16-3.11 \mathrm{~mm}$ (mid-sagittal regions) and 0.9-1.84 mm (lateral-median regions) \\
Pazera et al. & 2010 & CBCTs & $1.58 \mathrm{~mm}$ (95\% Cl 1.17-1.98) \\
Cakur et al. & 2011 & CBCTs & $0.5 \pm 0.49 \mathrm{~mm}$ \\
Pommer et al. & 2012 & CTs & $0.8-1.99 \mathrm{~mm}$ \\
Anduze-Acher et al & 2012 & CTs & $1.99 \pm 2.10 \mathrm{~mm}$ \\
Zheng-Ze Guo et al. & 2015 & CBCTs & $1.93 \pm 2.00 \mathrm{~mm}$ \\
Shih-Cheng Wen et al. & 2015 & CBCTs & $1.78 \pm 1.99 \mathrm{~mm}$ \\
Yen-Hua Lin et al. & 2015 & CBCTs & $1.32 \pm 0.87 \mathrm{~mm}$ \\
Insua et al. & 2017 & Cadavers & $1.36 \pm 0.42 \mathrm{~mm}$ \\
Lozano-Carrascal et al. & 2017 & CBCTs & $1.82 \pm 1.59 \mathrm{~mm}$ \\
Talo Jildirim et al. & 2017 & CBCTs & $4.19 \pm 5.84 \mathrm{~mm}$ \\
Present study & 2017 & CBCTs & $1.60 \pm 1.20 \mathrm{~mm}$ \\
\hline
\end{tabular}


width from mesial to distal, and they have no significant correlation with any of our parameters. Thickness of the mucosa and width of the maxillary sinus did not seem to correlate. Future studies including larger groups of participants should be necessarily conducted in order to establish additional possible correlations between the anatomical structures of the maxillary sinus and their variations.

\section{Availability of data and materials}

The data will not be shared, but are available upon request.

\section{Authors' contributions}

DK evaluated and selected the CBCT images for the present study. AK and SP conducted all the required measurements. All four authors interpreted and analyzed the data collected. KT critically revised and approved the article. All authors read and approved the final manuscript.

\section{Ethics approval and consent to participate}

Patient recruitment and data collection for this study took place at National and Kapodistrian University of Athens, School of Dentistry, Greece. The research was approved by the Ethics Committee of the National and Kapodistrian University of Athens, Greece, and all activities were conducted in full accordance with ethical principles, including the World Medical Association Declaration of Helsinki. We described the purpose of the study to patients, and the data obtained anonymously.

\section{Consent for publication}

Written informed consent was obtained from the patients for the publication of this study and any data.

\section{Competing interests}

Authors Demos Kalyvas, Andreas Kapsalas, Sofia Paikou, and Konstantinos Tsiklakis declare that they have no competing interests.

\section{Publisher's Note}

Springer Nature remains neutral with regard to jurisdictional claims in published maps and institutional affiliations.

\section{Author details}

${ }^{1}$ Department of Oral and Maxillofacial Surgery, School of Dentistry, National and Kapodistrian University of Athens, Greece, Thivon 2 str, 11527 Athens, Greece. ${ }^{2}$ Oral Diagnosis \& Radiology Clinic, School of Dentistry, National and Kapodistrian University of Athens, Greece, Thivon 2 str, 11527 Athens, Greece.

\section{Received: 29 January 2018 Accepted: 27 August 2018}

\section{Published online: 19 October 2018}

\section{References}

1. Testori T. Maxillary sinus surgery: Anatomy and advanced diagnostic imaging. J Implant and Reconstructive Dent. 2011;2:6-14.

2. Sargi ZB, Casiano RR. Surgical anatomy of the paranasal sinuses. In: Kountakis SE, Onerci TM, editors. Rhinologic and sleep apnea surgical techniques. New York: Springer; 2007. p. 17-26.

3. Bergh van den JPA, Bruggenkate ten CM, Disch FJM, Tuinzing DB. Anatomical aspects of sinus floor elevations. Clin Oral Impl Res. 2000;11: 256-65.

4. Gosau M, Rink D, Driemel O, Draenert FG. Maxillary sinus anatomy: a cadaveric study with clinical implications. Anat Rec (Hoboken). 2009; 292(3):352-4.

5. Guo Z-Z, Liu Y, Qin L, Song Y-L, Xie C, Li D-H. Longitudinal response of membrane thickness and ostium patency following sinus floor elevation: a prospective cohort study. Clin. Oral Impl. Res. 2015;00:1-6.

6. D R, Borgonovo AE, Cicciù M, Re D, Rizza F, Frigo AC, Maiorana C. Maxillary sinus septa and anatomic correlation with the Schneiderian membrane. J Craniofac Surg. 2015;26(4):1394-8.
7. Lin Y-H, Yang $Y-C$, Wen S-C, Wang H-L. The influence of sinus membrane thickness upon membrane perforation during lateral window sinus augmentation. Clin. Oral Impl. Res. 2015;00:1-6.

8. Kim SH, Kim KH, Seo BM, et al. Alveolar bone regeneration by transplantation of periodontal ligament stem cells and bone marrow stem cells in a canine peri-implant defect model: a pilot study. J Periodontol. 2009;80(11):1815-23.

9. Cakur B, Sümbüllü MA, Durna D. Relationship among Schneiderian membrane, Underwood's septa, and the maxillary sinus inferior border. Clin Implant Dent Relat Res. 2013;15(1):83-7.

10. Shanbhag S, Karnik P, Shirke P, Shanbhag V. Cone-beam computed tomographic analysis of sinus membrane thickness, ostium patency, and residual ridge heights in the posterior maxilla: implications for sinus floor elevation. Clin Oral Impl Res. 2014;25:755-60.

11. Yoo JY, Pi SH, Kim YS, Jeong SN, You HK. Healing pattern of the mucous membrane after tooth extraction in the maxillary sinus. J Periodontal Implant Sci. 2011;41(1):23-9.

12. Janner SFM, Caversaccio MD, Dubach P, Sendi P, Buser D, Bornstein MM Characteristics and dimensions of the Schneiderian membrane: a radiographic analysis using cone beam computed tomography in patients referred for dental implant surgery in the posterior maxilla. Clin. Oral Impl. Res. 2011;22:1446-53.

13. Cagici CA, Yilmazer C, Hurcan C, Ozer C, Ozer F. Appropriate interslice gap for screening coronal paranasal sinus tomography for mucosal thickening. Eur Arch Otorhinolaryngol. 2009;266(4):519-25.

14. Eggesbø HB. Radiological imaging of inflammatory lesions in the nasal cavity and paranasal sinuses. Eur Radiol. 2006;16:872-88.

15. Lozano-Carrascal N, Salomó-Coll O, Gehrke SA, Calvo-Guirado JL, HernándezAlfaro F, Gargallo-Albiol J. Radiological evaluation of maxillary sinus anatomy: a cross-sectional study of 300 patients. Ann Anat. 2017;214:1-8. https://doi.org/ 10.1016/.jaanat.2017.06.002. Epub 2017 Jul 29

16. Vallo J, Suominen-Taipale L, Huumonen S, Soikkonen K, Norblad A. Prevalence of mucosal abnormalities of the maxillary sinus and their relationship to dental disease in panoramic radiography: results from the health 2000 Health Examination Survey. Oral Surg Oral Med Oral Pathol Oral Radiol Endod. 2010;109(3):e80-7.

17. Yildirim TT, Güncü GN, Göksülük $D$, Tözüm MD, Colak M, Tözüm TF. The effect of demographic and disease variables on Schneiderian membrane thickness and appearance. Oral Surg Oral Med Oral Pathol Oral Radiol. 2017; 124:568-76.

18. Pazera P, Bornstein MM, Pazera A, Sendi P, Katsaros C. Incidental maxillary sinus findings in orthodontic patients: a radiographic analysis using conebeam computed tomography (CBCT). Orthod Craniofac Res. 2011;14:17-24.

19. Tos M, Mogensen C. Mucus production in the nasal sinuses. Acta Otolaryngol Suppl. 1979:360:131-4

20. M A, Massei G, Morra M, Cardesi E, Romano F. Correlation between gingival phenotype and Schneiderian membrane thickness. Int J Oral Maxillofac Implants. 2008;23(6):1128-32.

21. Pommer B, Unger E, Suto D, Hack N, Watzek G. Mechanical properties of the schneiderian membrane in vitro. Clin Oral Implants Res. 2009;20:633-7.

22. Pommer B, Dvorak G, Jesch P, Palmer RM, Watzek G, Gahleitner A. Effect of maxillary sinus floor augmentation on sinus membrane thickness in computed tomography. J Periodontol. 2012;83:551-6.

23. Anduze-Acher G, Brochery B, Felizardo R, Valentini P, Katsahian S, Bouchard $P$. Change in sinus membrane dimension following sinus floor elevation: a retrospective cohort study. Clin. Oral Impl. Res. 2013;24:1123-9.

24. Wen S-C, Lin Y-H, Yang Y-C, Wang H-L. The influence of sinus membrane thickness upon membrane perforation during transcrestal sinus lift procedure. Clin. Oral Impl. Res. 2015;26:1158-64.

25. Insua A, Monje-Gil F, García-Caballero L, Caballé-Serrano JJ, Wang HL, Monje A. Mechanical characteristics of the maxillary sinus Schneiderian membrane ex vivo. Clin Oral Investig. 2017; https://doi.org/10.1007/s00784-017-2201-4. 